\title{
Uncovering ITIL claims: IT executives' perception on benefits and Business-IT alignment
}

\author{
Mauricio Marrone $\cdot$ Lutz M. Kolbe
}

Received: 15 November 2009/Accepted: 27 May 2010/Published online: 29 June 2010

(C) The Author(s) 2010. This article is published with open access at Springerlink.com

\begin{abstract}
Over $45 \%$ of companies are estimated to use IT Service Management (ITSM) frameworks, yet, these frameworks can be imitated and hence the competitive advantage gained from these will quickly become obsolete. Therefore, research on the benefits of ITSM must focus on both operational and strategic benefits. An international survey of 441 firms was conducted to examine the benefits that IT Infrastructure Library (ITIL), the de-facto ITSM framework, provided to the IT organizations. The research focused on how (1) operational benefits, and, (2) strategic positioning of the IT organizations, specifically how the perceived level of Business-IT alignment maturity evolved as the adoption of ITIL increased. Results indicate that as the adoption of ITIL increased, the number of realized operational benefits increased, as well as the levels of maturity of the Business-IT alignment. This indicates that the further the implementation of ITIL the greater the operational and strategic benefits to the organization. Implications for practitioners and researchers are also discussed.
\end{abstract}

Keywords IT infrastructure library · ITIL · Business-IT alignment · Business process management $\cdot$ BPM

\section{Introduction}

In the 1980s manufacturing companies implemented improvement programs such as TQM (Total Quality Management), Lean Manufacturing, JIT (Just-In-Time)

\footnotetext{
M. Marrone $(\bowtie) \cdot$ L. M. Kolbe

University of Göttingen, Platz der Göttingen Sieben 5,

37073 Göttingen, Germany

e-mail: mmarron@uni-goettingen.de

L. M. Kolbe

e-mail: 1kolbe@uni-goettingen.de
} 
amongst others. Companies implemented such programs in order to achieve competitive advantage and become "world-class" through the achievement of operational improvements. However, in their study, Hubiak and O'Donnell (1996) argue the majority of the implementations of such programs were not successful and did not provide the expected benefits. Hayes and Pisano (1994) state that "if managers pin their competitive hopes on the implementation of a few best-practice approaches, they implicitly abandon the central concept of strategy in favor of a generic approach to competitive success". Porter (1996) argues that focusing on operational improvements is not a replacement of a strategy and that the main focus of the business should be on the later.

Nowadays, the usage of IT best practices is becoming more and more common. Several studies have focused on the adoption of IT Service Management (ITSM) as well as a specific service oriented best practices. Winniford et al. (2009) claim that around $45 \%$ of US companies are using an ITSM while $15 \%$ are planning its usage. The IT Governance Institute (2008) estimates that the ITSM framework with the highest adoption rate is IT Infrastructure Library (ITIL) with $24 \%$, followed by Control Objectives for Information and related Technology (CobiT) with an adoption rate of $14 \%$.

When analyzing the benefits that such best practices have on the organizations that implement them, it is not only important to understand if best practices can provide operational benefits, but also to examine if they can provide a greater alignment between the IT organization and the business.

To date there have been few academic studies on the benefits on ITSM, yet, practitioners and researchers are interested in understanding the possible benefits realized by companies which adopted an ITSM, specifically those companies which have adopted ITIL. Moreover, importance is given to the understanding of how operational benefits evolve as companies increase the adherence to the guidelines to the ITIL model. Also of interest is the perception by IT managers of the alignment of IT and the business and, how this perception develops as companies increase their adherence to the model.

The research methodology of a large scale international survey has not yet been employed. Therefore, this research, using empirical data gathered from a survey with major companies from various industries, and set out to understand the following:

1. How is the Business-IT alignment perceived at different levels of maturity of the ITIL implementation?

2. How does the total number of realized benefits develop as the maturity of the ITIL implementation increases?

In this context, this paper begins with a literature review on IT Service Management as well as benefits of the usage of ITIL and on Business-IT alignment. This is followed by a description of the methodology used for this research. Results of the survey are then analyzed and outcomes are discussed. Before the limitations and the future research sections conclusions are drawn. 


\section{Related research}

IT Service Management can be defined as "a set of processes that cooperate to ensure the quality of live IT services, according to the levels of service agreed to by the customer" (Young 2004) Conger et al. (2008) add that ITSM "focuses on defining, managing, and delivering IT services to support business goals and customer needs, usually in IT Operations". Since ITSM is process focused, it shares a joint ideology with process improvement movements such as Business Process Management (BPM; Brenner 2006; Galup et al. 2009).

Service oriented IT Management can be seen as a philosophy for an orientation towards market, service, lifecycle and processes (Zarnekow et al. 2005). First, there is a market orientation, which implies that there is a customer-supplier relation instead of a relationship as project partners. Second, there is a service orientation, which means service providers have service portfolios instead of project portfolios. These service portfolios include all of the IT services offered by the provider. Third, the focus is on the service lifecycle hence, the ITSM provide a methodical approach to the management of IT services-from design, implementation, operation to continual improvement. It does not only focus on the technical aspects of IT but also allows the alignment of the service and functions provided by IT within the organization. The main focus of the management of IT services is on the costs of the whole lifecycle, not merely on the costs of development. This leads to a lifecycle orientation. Fourth is the process orientation, so that the IT organization is oriented on processes and not on functional structures.

There are various concepts of ITSM. The most common approach is the ITIL which is a de facto standard for IT Service Providers (Hochstein et al. 2005; IT Governance Institute 2008). Various ITSM frameworks have been developed using ITIL as a reference, such as Hewlett-Packard (HP ITSM Reference model), IBM (IT Process Model) and Microsoft's MOF (van Bon et al. 2007).

The current version of ITIL, Version 3, was published in May 2007. It consists of 26 sections which are included in the following five services: Service Strategy, Service Design, Service Transition, Service Operation and Continual Service Improvement. The earlier version, Version 2, has a total of ten processes in two main domains: Service Support and Service Delivery.

Academic research on ITIL is still in its early stages despite its numerous appearances in the popular press and practitioners' magazines. Existing academic literature merely presents the description of the areas documented on ITIL (e.g. Cervone 2008) or analyzes adopters of ITIL through case studies (e.g. Hochstein et al. 2005; Marrone et al. 2010). A summary of benefits of ITIL found in academic literature published in peer-reviewed journals and conferences is shown in Table 1.

To achieve a superior profitability it is not enough to receive benefits at an operational level. Changes at an operational level, such as the usage of best practices, can be quickly imitated as other companies observe that the usage of a best practice gives a company the competitive advantage. The greater the usage of best practices the more similar companies becomes. Porter (1996) proposed that improvements created by best practice do not lead to improvements for any organization. Porter argues that a company should focus on both the operational 
Table 1 Summary of benefits of ITIL

\begin{tabular}{|c|c|c|c|c|c|}
\hline Improvement of... & $\begin{array}{l}\text { Hochstein } \\
\text { et al. (2005) }\end{array}$ & $\begin{array}{l}\text { Potgieter } \\
\text { et al. }(2005)\end{array}$ & $\begin{array}{l}\text { Marrone } \\
\text { et al. (2010) }\end{array}$ & $\begin{array}{l}\text { Cater-Steel } \\
\text { et al. (2008) }\end{array}$ & $\begin{array}{l}\text { Cervone } \\
(2008)\end{array}$ \\
\hline Service quality & $\mathrm{X}$ & $\mathrm{X}$ & $\mathrm{X}$ & $\mathrm{X}$ & $\mathrm{X}$ \\
\hline Standardization of service & $\mathrm{X}$ & & $X$ & $X$ & \\
\hline Customer satisfaction & & $\mathrm{X}$ & $\mathrm{X}$ & $\mathrm{X}$ & \\
\hline Return on investment & & & $\mathrm{X}$ & $\mathrm{X}$ & $\mathrm{X}$ \\
\hline Reduction of downtime & & & & $\mathrm{X}$ & $\mathrm{X}$ \\
\hline $\begin{array}{l}\text { Benefited from best practice } \\
\text { experience of others }\end{array}$ & $\mathrm{X}$ & & & & \\
\hline Financial contribution control & & & & $\mathrm{X}$ & \\
\hline First-call resolution rate & & & & $\mathrm{X}$ & \\
\hline Morale of IT & & & & $\mathrm{X}$ & \\
\hline
\end{tabular}

effectiveness and the strategic positioning and that continual improvement is necessary to stay relevant in the market.

IT organizations that have implemented a best practice such as ITIL need to have a dual focus. They need to concentrate not only on the operational level benefits achieved by the implementation of best practices but also on their strategic level positioning to develop a unique and valuable stance relevant to the customer. In other words, it is also important for the IT organization to be more than a mere support for the business, but rather a proactive organization that is responsive to the needs of the business and the market.

Business-IT alignment engages in creating and supporting the activities that fit the strategy between the business and IT. It can be defined as "The extent to which the IS strategy supports, and is supported by, the business strategy" (Luftman et al. 1993). The strategic outcome is that the overall business benefits from effective IT functioning and IT benefits from being integral to the business plans of the company. Two directions of alignment can be identified; one on the way IT is aligned to business, and the other, on the way business can be aligned to IT (Luftman 2003). Both directions are equally important.

Business-IT alignment has been shown to have a positive effect on business performance (Sabherwal and Chan 2001). It provides a competitive advantage and increases profitability (Henderson et al. 1996), and is a key factor for successful IT systems implementations (Boynton et al. 1994).

Currently there is a debate in the literature about how alignment should be measured and what should be measured. In a review of the various measuring approaches, Avison et al. (2004) conclude that there is no agreement on the factors that can measure Business-IT alignment.

Researchers such as Tallon et al. (2000) have assessed strategic alignment using a single item. This approach has been supported by Venkatraman and Ramanujam (1987) who found a correlation between the reality and the perception of executives.

On the other hand, researchers such as Das et al. (1991), Reich and Benbasat (2000) and Luftman (2003) use multi-dimensional scales to measure the alignment. 
Das et al. (1991) identify five dimensions: formality, scope, participation, influences, and co-ordination. Reich and Benbasat (2000) suggest four elements; shared domain knowledge, IT implementation success, communication between IT and the business, and connection between IT and business planning.

Luftman (2004) considers six criteria when measuring the alignment. These are: Communication Maturity, Competence/Value Measurement Maturity, Governance Maturity, Partnership Maturity, Scope and Architecture Maturity and Skills Maturity. However, Fimbel (2007) observes that professionals do not use the available alignment models because these do not enable them to shed light on company's practices. He proposes the Dynamic and Global Alignment Model (DyGAM) developed from an international survey conducted amongst 150 companies.

While there has been no agreement on how to measure the Business-IT alignment, there have been attempts to understand whether ITIL contributes to this alignment. Kashanchi and Toland (2006) conducted an exploratory analysis of data gained from interviews with three experts and concluded that ITIL has the ability to support business strategy and to improve IT strategy.

Until now there has been no research that has measured the benefits and the Business-IT alignment and their relation to the maturity of the ITIL implementation. Similarly, the methodology of a large scale survey involving a range of countries and industries has not be undertaken. This literature review leads to the research hypotheses, which are presented in the following section.

\section{Research design}

Rather than merely analyzing the operational level improvements, which may be achieved through the adoption of ITIL, attention should also be placed on the strategy level improvements. This section describes the levels of adoption, generally known as maturity model, as well as specifying the hypotheses derived from the two research questions listed in the introduction. A total of four hypotheses are formulated.

\subsection{Maturity levels}

To comprehend at which level of adherence or maturity companies are in when adopting the ITSM model, various researchers including Cater-Steel et al. (2006) and Marrone et al. (2010) have used the Maturity Model. The Maturity Model presented in these studies is based on the model from CobiT and Capability Maturity Model Integration (CMMI). These levels are intended as profiles of IT processes. Companies would identify these levels as a description of their current state. Table 2 covers the definitions for each level of the maturity model.

Similarly, to understand at which level of maturity companies are regarding their Business-IT alignment, the levels proposed by Luftman's (2001) Strategy Alignment Maturity Model (SAMM) are used. The five levels of Business-IT alignment 
Table 2 Maturity model levels with definitions

\begin{tabular}{lll}
\hline Level & Level name & Definitions \\
\hline 0 & Non-existent & Management of processes is not applied at all \\
1 & Initial/ad hoc & Processes are ad hoc and disorganized \\
2 & Repeatable & Processes follow a standard, are documented and understood \\
3 & Defined & Processes are documented and monitored for compliance \\
4 & Managed & Management monitors and measures according to metrics \\
& Optimized & established on the previous level \\
5 & & Good practices are followed and automated \\
\hline
\end{tabular}

maturity are: (1) Initial/Ad Hoc, (2) Committed, (3) Established/Focused, (4) Improved/Managed, and (5) Optimized.

\subsection{Hypotheses}

The research focuses on the IT organization's perception of the Business-IT alignment and aims to understand which effect, if any, the increase of the adoption of the ITIL model has on the perception of the Business-IT alignment. We hypothesize the following:

H1 Based on the perception of the IT organization, as the maturity level of ITIL increases, the Business-IT alignment increases.

Additionally, the focus of our research is to understand the progression of the 'total impact of realized benefits' to the companies rather than the 'perception of the benefits realized' in the individual areas. Consequently, the total number of realized benefits due to the implementation of ITIL is calculated for each company. The same approach is used for the number of benefits supported by metrics and the number of benefits acknowledged by the business. Therefore, the following hypothesis is suggested:

H2a As the maturity level of ITIL increases, so does the quantity of realized benefits at the earlier levels of implementation, while on the later levels, the quantity of realized benefits stays nearly constant.

We also expect that at later levels of maturity the number of realized benefits that are supported by metrics will be observed, rather than on the initial levels of maturity. Similarly, the business may recognize the benefits of the ITIL implementation in the later levels of adoption, possibly due to a better BusinessIT alignment, which is a proposed benefit of ITIL. Therefore, the following hypotheses are suggested:

H2b As the maturity level of ITIL increases, so does the usage of metrics to measure the realized benefits.

H2c As the maturity level of ITIL increases, so does the acknowledgement by the business of the benefits of ITIL. 


\section{Methodology}

\subsection{Design}

The online questionnaire was made available in the months of April and May 2009. An invitational email was sent to individuals who were on the mailing lists of Hornbill and the IT Service Management Forum (itSMF) in the United States of America and United Kingdom. Additionally, in an attempt to expand the findings of this research, the survey was announced in various internet groups and forums whose sole topic was ITIL. Using this approach the research findings are applicable to a greater population of ITIL users, rather than solely to the members of certain mailing lists or groups. The target participant would be ITIL champions for their organization and would be heavily involved in the implementation of ITIL.

The structure of the questionnaire addressed many aspects of ITIL, its adoption, usage, implementation and maturity, as well as effectiveness of processes and realized benefits. It also covered the topics of Business-IT alignment and service desk usage. The survey contained questions to which responses used Likert scales, nominal scales and open-ended questions.

The following three categories were used for the study:

1. Rate the perception of the maturity of your ITIL implementation (using a scale based on the Maturity Model).

2. Choose the perceived level of Business-IT alignment (based on Luftman's (2001) SAMM levels with each level and their definitions displayed for further information).

3. Select realized benefits that could be achieved due to the adoption of ITIL (benefits listed on the survey are those found on the Table 1).

"Appendix" contains an extract of the original survey used. Question 1 was used to understand the maturity of the ITIL implementation. Question 2 was used to understand the current level of Business-IT alignment. Question 3 was used to record the benefits which were realized. There were two follow up questions. Question 4 was used to understand if the benefits that had been realized had been quantified through the usage of metrics. Question 5 asked whether the benefits that had been realized had also been acknowledged by the business.

Therefore, for this study the perceived maturity level is the independent variable, while the perceived realized benefits and the perceived Business-IT alignment are the dependent variables.

Questions on benefits were validated by IT service experts in a pilot survey that was carried out at the CeBIT fair in Hannover, Germany in February 2009. From the feedback received, a small number of word changes were completed.

\subsection{Respondents' profile}

More than 5,000 invitations were sent out to members of the itSMF UK and US and to the mailing list of Hornbill. Out of the 784 IT executives who started the survey, 503 completed and submitted the survey. Partially completed surveys were not used 
for the study. Four-fifth of those who completed the survey were directly invited to participate in the survey, the remainder were recruited through the forum posting. The return rate of the survey invitations was less than eight percent. One hundred and 93 of the respondents used ITIL Version 3, while a total of 248 used Version 2. Those not using ITIL were excluded for this study. The final sample size was 441.

Respondents were asked about their companies' industry, number of sites supported by IT, number of employees in the company as well as their title and their location. Table 3 shows the profile of the respondents. In the sample around threefourths of those surveyed were from the technology, public, financial and banking sectors. Other industries include the professional, retail and manufacturing industries.

Nearly $70 \%$ of the respondents had ten or more sites supported by central IT, and close to $20 \%$ had two to five sites. Almost $45 \%$ of those interviewed worked in a company which had more than 10,000 employees. The job roles of those interviewed are also shown. Of those surveyed $33 \%$ were IT managers, while $23 \%$ were Process Specific Managers. The majority of the answers received were from IT job roles. Due to the usage of mailing lists and posting of invitations to the survey on English speaking websites, the majority of answers came from the United Kingdom (53\%) and United States $(35 \%)$ with various answers coming from Canada, India and Ireland.

\section{Results}

An exploratory analysis was conducted for each variable to test for normality. Both, the Kolmogorov-Smirnov and the Shapiro-Wilk tests showed significance for the perceived Business-IT alignment $(p<0.001)$ and for the realized benefits of ITIL $(p<0.001)$. As the data was non-normal, the Kruskal-Wallis, a non-parametric one way analysis of variance, was used to study the data. If the data using the KruskalWallis showed significant differences between the groups, the Mann-Whitney $U$ test is applied.

As the study was concerned with how the nominated variables were impacted as the ITIL implementation increases, caution was taken with the choice of test measures. The Mann-Whitney $U$ tests inflates the Type I error rate, so care was taken in the choice of comparisons made.

The suggested comparisons are between the first and middle level of ITIL implementation maturity, the first and last level of ITIL implementation maturity, and between the middle and final level of ITIL implementation maturity. Therefore the following three tests were conducted:

- Test 1: Level 1 (Initial) compared to Level 3 (Defined).

- Test 2: Level 1 (Initial) compared to Level 5 (Optimized).

- Test 3: Level 3 (Defined) compared to Level 5 (Optimized).

Since three tests were conducted, a Bonferroni correction is applied. Due to this correction, rather than using the critical level of significance of 0.05 , all effects were reported at 0.0167 level of significance. All reported $p$ values are using two-tailed 
Table 3 Profile of responding organizations $(n=441)$

\begin{tabular}{ll}
\hline Industry & Percent \\
\hline Technology & 32 \\
Public & 23 \\
Financial and banking & 19 \\
Manufacturing & 5 \\
Other & 5 \\
Retail and distribution & 4 \\
Professional & 4 \\
Utility & 2 \\
Entertainment and hospitality & 2 \\
Healthcare & 2 \\
Telecommunication & 2 \\
\hline
\end{tabular}

\begin{tabular}{|c|c|}
\hline Countries & Percent \\
\hline United Kingdom & 53 \\
\hline United States of America & 35 \\
\hline Canada & 1 \\
\hline India & 1 \\
\hline Ireland & 1 \\
\hline Other & 9 \\
\hline Number of sites & Percent \\
\hline $10+$ & 69 \\
\hline $2-5$ & 18 \\
\hline $6-10$ & 7 \\
\hline 1 & 6 \\
\hline Number of employees & Percent \\
\hline $10,000+$ & 42 \\
\hline $1,001-5,000$ & 19 \\
\hline $5,001-10,000$ & 17 \\
\hline $101-500$ & 9 \\
\hline $501-1,000$ & 8 \\
\hline$<100$ & 5 \\
\hline Job role & Percent \\
\hline IT manager & 33 \\
\hline Process specific manager e.g. change & 23 \\
\hline Service delivery manager & 19 \\
\hline IT director-organisation level & 13 \\
\hline HelpDesk/service desk manager & 9 \\
\hline HelpDesk/service desk operative & 3 \\
\hline
\end{tabular}


Monte Carlo $p$ values with a confidence level of $99 \%$ and a number of samples of 10,000. This method was used because of the large sample size.

Additionally, to understand the trends in the data the Jonckheere-Terpstra test was used. Lastly, $r$ was used to measure the strengths of a relationship between variables (Rosenthal 1991 p. 19). Cohen suggests that the sizes of the effect are small (0.1), medium (0.3) or large (0.5). If $r$ is a negative number this reveals that the data lies on a straight line with a negative slope.

In the next sections the following abbreviations are used: $\mathrm{H}$ corresponds to the Kruskal-Wallis statistic, $U$ represents the Mann-Whitney $U$ statistic, SE is the Standard Error, while $J$ symbolizes the observed Jonckheere-Terpstra statistic.

\subsection{Business-IT alignment and maturity level (H1)}

Table 4 displays the means and medians for the perceived Business-IT alignment. In general, the perceived Business-IT alignment is significantly affected by the implementation maturity of ITIL $(\mathrm{H}(4)=77.43, p<0.001)$. Mann-Whitney tests were also used to follow up this finding.

Table 5 shows the results from the selective comparisons. It can be observed that between Level 1 (Initial) and Level 3 (Defined) there was significance ( $U=1,411$, $r=-.21$ ). When comparing Level 1 (Initial) with Level 5 (Optimized) significance

Table 4 Descriptive statistics of Business-IT alignment $(n=441)$
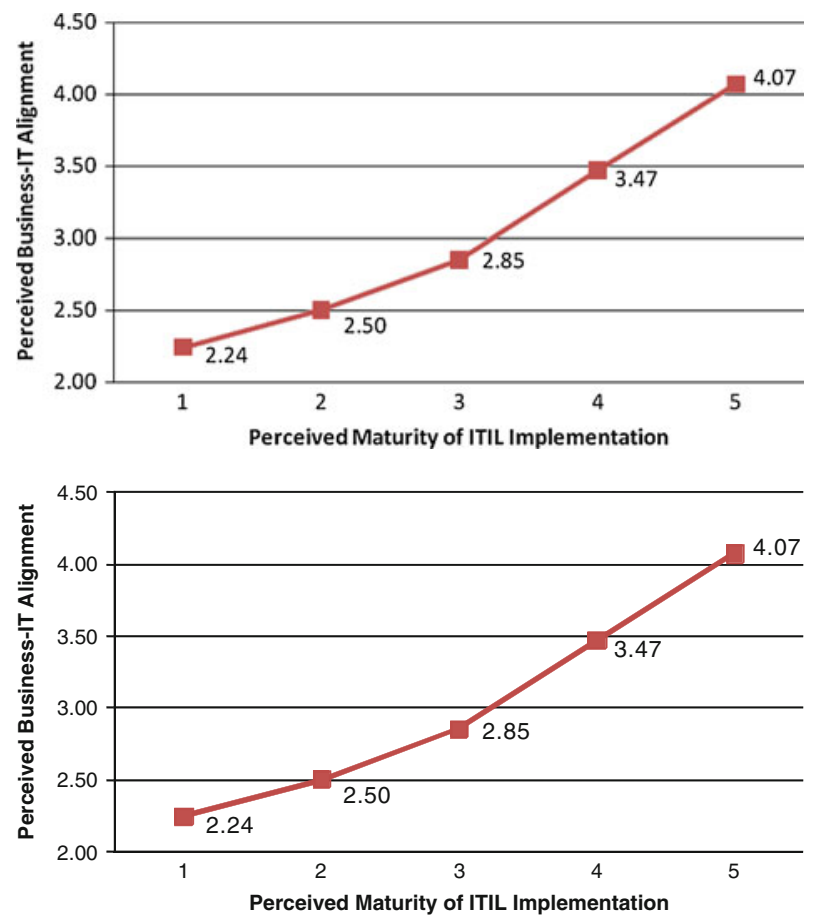
Table 5 Mann-Whitney $U$ test results for perceived Business-IT alignment maturity levels $(n=441)$

\begin{tabular}{|c|c|c|c|c|c|c|c|c|c|}
\hline & \multicolumn{3}{|c|}{$\begin{array}{l}\text { Level } 1 \text { compared with } \\
\text { Level } 3\end{array}$} & \multicolumn{3}{|c|}{$\begin{array}{l}\text { Level } 1 \text { compared } \\
\text { with Level } 5\end{array}$} & \multicolumn{3}{|c|}{$\begin{array}{l}\text { Level } 3 \text { compared with } \\
\text { Level } 5\end{array}$} \\
\hline & $U$ & $p$ & $r$ & $U$ & $p$ & $r$ & $U$ & $p$ & $r$ \\
\hline Business-IT alignment (H1) & $1,410.5$ & $0.010^{*}$ & -0.21 & 331.5 & $0.000 *$ & -0.55 & $1,620.5$ & $0.000^{*}$ & -0.44 \\
\hline
\end{tabular}

* Significance at 0.0167

can be observed with a large effect size $(U=332, r=-.55)$. Lastly, comparing Level 3 (Defined) with Level 5 (Optimized) significance can be observed $(U=1,620, r=-.44)$. The greatest increase of the perceived level of maturity can be seen when comparing Level 3 (Defined) and Level 5 (Optimized).

Jonckheere's test revealed a significant trend in the data. As the level of maturity goes up, the median of the perceived Business-IT alignment increases $(J=49,777$, $z=8.79, r=.42$ ). We can conclude that the perceived Business-IT alignment increases as the maturity of implementation increases.

\subsection{Number of realized benefits and maturity levels $(\mathrm{H} 2)$}

When conducting the Kruskal-Wallis test, the number of realized benefits is significantly affected by the level of implementation maturity $[\mathrm{H}(4)=80.12$, $p<0.001$ for the total number of realized benefits $(\mathrm{H} 2 \mathrm{a}), \mathrm{H}(4)=98.44, p<0.001$ for realized benefits using metrics $(\mathrm{H} 2 \mathrm{~b}), \mathrm{H}(4)=62.95, p<0.001$ for realized benefits acknowledged by the business $(\mathrm{H} 2 \mathrm{c})]$. Table 6 presents the means, standard error and medians for the perceived realized benefits.

As shown in Table 7, the number of realized benefits (H2a) is significantly higher when comparing Level 1 (Initial) with Level 3 (Defined) of maturity of implementation. Based on Cohen's benchmark, there is a medium to large change on the number of realized benefits as maturity increases $(U=778, r=-.40)$. One can also observe this when comparing Level 1 (Initial) with Level 5 (Optimized; $U=347, r=-.46$ ). Finally, when comparing Level 3 (Defined) with Level 5 (Optimized) no significance can be determined ( $U=2,831, r=-.15)$. Yet, when comparing the same levels, significance can be observed when examining the number of realized benefits that have been measured using metrics $(\mathrm{H} 2 \mathrm{~b}$; $U=2,400, r=-.24$ ) as well as when observing the number of realized benefits that have been acknowledged by the business (H2c; $U=2,386, r=-.24$ ). Significance for the total realized benefits backed by metrics $(\mathrm{H} 2 \mathrm{~b})$ can be seen also when comparing Level 1 (Initial) with Level 3 (Defined; $U=838, r=-.37$ ). Additionally, significance can also be observed for the total realized benefits acknowledged by business (H2c) when comparing Level 1 (Initial) with Level 3 (Defined; $U=1,325.5, r=-.22$ ).

Jonckheere's test shows a significant trend in the data. As the level of maturity goes up, the median number of realized benefits increases $(\mathrm{H} 2 \mathrm{a} ; J=49,784$, $z=11.44, r=.41)$, the median number of realized benefits backed by metrics increases $(\mathrm{H} 2 \mathrm{~b} ; J=51,503, z=11.69, r=.46)$, and finally, the median number of 
Table 6 Descriptive statistics of realized benefits $(n=441)$
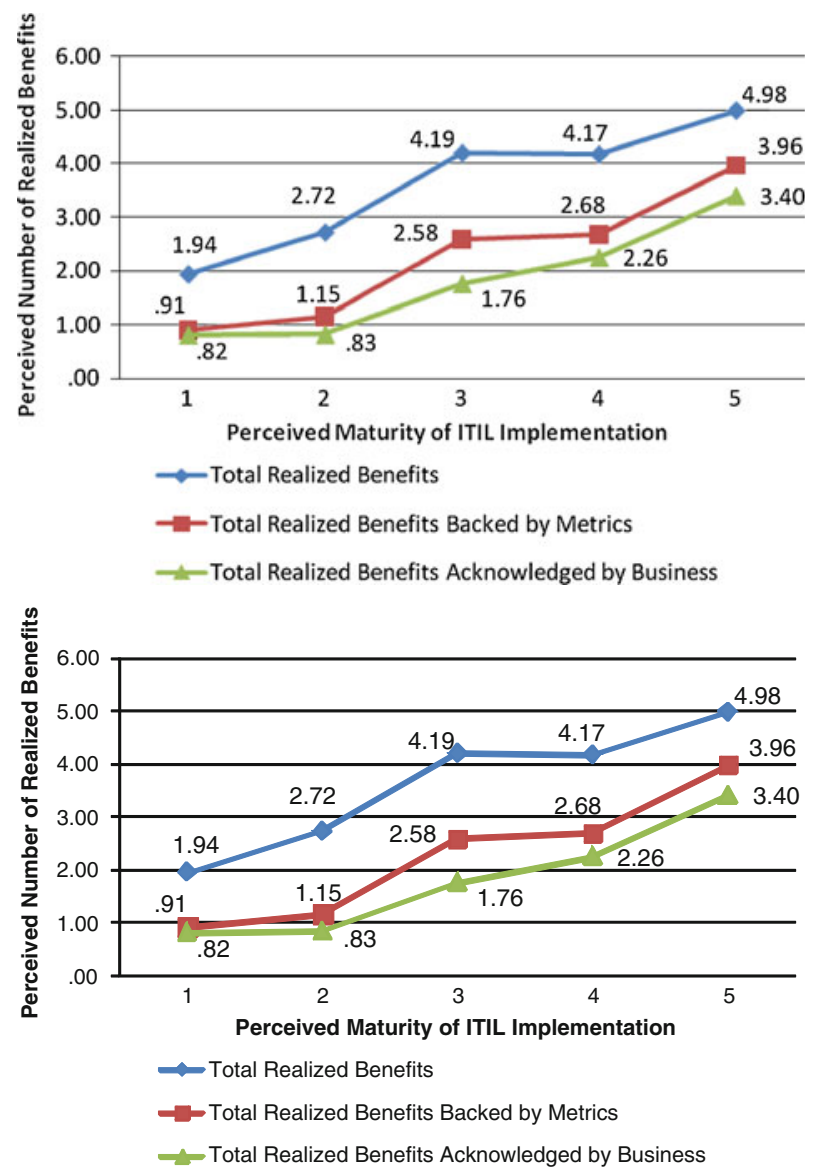

Table 7 Mann-Whitney $U$ test results for total number of perceived realized benefits and maturity levels $(n=441)$

\begin{tabular}{|c|c|c|c|c|c|c|c|c|c|}
\hline \multirow[t]{2}{*}{... per company } & \multicolumn{3}{|c|}{$\begin{array}{l}\text { Level } 1 \text { compared with } \\
\text { Level } 3\end{array}$} & \multicolumn{3}{|c|}{$\begin{array}{l}\text { Level } 1 \text { compared } \\
\text { with Level } 5\end{array}$} & \multicolumn{3}{|c|}{$\begin{array}{l}\text { Level } 3 \text { compared with } \\
\text { Level } 5\end{array}$} \\
\hline & $U$ & $p$ & $r$ & $U$ & $p$ & $r$ & $U$ & $p$ & $r$ \\
\hline Total realized benefits $(\mathrm{H} 2 \mathrm{a})$ & 777.5 & $0.000 *$ & -0.40 & 347.0 & $0.000^{*}$ & -0.46 & $2,830.5$ & 0.068 & -0.15 \\
\hline $\begin{array}{l}\text { Total realized benefits } \\
\text { backed by metrics }(\mathrm{H} 2 \mathrm{~b})\end{array}$ & 838.0 & $0.000^{*}$ & -0.37 & 324.0 & $0.000^{*}$ & -0.48 & $2,400.0$ & $0.002 *$ & -0.24 \\
\hline $\begin{array}{l}\text { Total realized benefits } \\
\text { acknowledged by business } \\
\text { (H2c) }\end{array}$ & $1,325.5$ & $0.000^{*}$ & -0.22 & 432.0 & $0.000^{*}$ & -0.40 & $2,386.0$ & $0.001 *$ & -0.24 \\
\hline
\end{tabular}

* Significance at 0.0167 
realized benefits acknowledged by business increases $(\mathrm{H} 2 \mathrm{c} ; J=48,387, z=9.73$, $r=.38)$.

We can conclude that as the level of maturity increases, so does the number of realized benefits and on later levels of maturity, specifically between the maturity Level 3 (Defined) and Level 5 (Optimized), companies concentrate more on using metrics and on showing the realized benefits to the business.

\section{Discussion}

In this research we focus on ITIL and the benefits it provides to the IT organization. Our research looks at how the implementation of ITIL may impact both factors: the operational effectiveness and strategic positioning. The research concentrates on the Business-IT alignment because it helps to support the services provided by IT to meet the needs of the business. This may provide the organization with a sustainable competitive advantage.

In general, the results of the current study confirm H1. H1 states that as the maturity of ITIL increases, so does the Business-IT alignment. It is shown that companies that are highly mature in the ITIL implementation are also highly aligned organizations. Of importance is that the greatest increase in the perceived level of maturity is seen in the later stages of maturity, Level 3 (Defined) and Level 5 (Optimized). These results confirm the exploratory research carried out by Kashanchi and Toland (2006).

Additionally, results from $\mathrm{H} 2 \mathrm{a}, \mathrm{H} 2 \mathrm{~b}$ and $\mathrm{H} 2 \mathrm{c}$ are statistically significant. $\mathrm{H} 2 \mathrm{a}$ explores the effect that the ITIL maturity has on the total number of realized benefits, while $\mathrm{H} 2 \mathrm{~b}$ and $\mathrm{H} 2 \mathrm{c}$ concentrates on the number of realized benefits backed by metrics and acknowledged by the business, respectively. The fact that there are benefits gained from the adoption of ITIL agrees with the results from individual case studies on the effectiveness of ITIL undertaken by Potgieter et al. (2005) and Spremic et al. (2008).

As observed in the results of $\mathrm{H} 2 \mathrm{a}$, the number of realized benefits increases as the maturity level increases. However, there was no significance when comparing the later levels of maturity, Level 3 (Defined) with Level 5 (Optimized). While no significant increase in the number of realized benefits can be observed in the later stages, between Level 3 (Defined) and Level 5 (Optimized) significant progress can be observed in other areas. These are:

1. The usage of metrics to support the realized benefits $(\mathrm{H} 2 \mathrm{~b})$. The usage of metrics leads to improved decision making and problem solving (Banker et al. 2004), the survival and prosperity of organizations (Kaplan and Norton 1996), and more importantly, it encourages the realignment of strategy (Neely et al. 1994).

2. Acknowledgement of the benefits realized by the business (H2c) and shows that there is a movement towards a higher Business-IT alignment.

All results from this study suggest, ITIL not only provide various benefits at operational level but also contributes to the strategic positioning. It does this by improving the Business-IT alignment which allows IT to enable the business in its 
creation of a sustainable competitive advantage. Additionally, it points towards a greater control of IT processes which allows IT to respond to the environmental uncertainty faced by the business. Furthermore, as proposed by Porter (1996), the strategic alignment between the Business and IT makes operational improvements more effective.

The study provides a contribution to both research and practice. The contribution to research is twofold. It provides a collection of nine key benefits (see Table 1) of ITSM and ITIL by using suggestions made by Hochstein et al. (2005), Potgieter et al. (2005), Marrone et al. (2010), Cater-Steel et al. (2008) and Cervone (2008). It also delivers insight into the perception of the effectiveness of ITIL, the perception of the progress of the maturity of the Business-IT alignment, as well as filling a research gap. Additionally, this research opens the path for future research.

In practice, the findings can serve as a guideline for IT managers who are considering adoption or who already have adopted ITIL. Three trends must be considered by IT managers:

1. the IT organization will receive various operational benefits in the early stages of implementation

2. in the later stages of implementation the usage of metrics to measure the benefits as well as the benefits acknowledged by business will continue to increase; and

3. the Business-IT alignment will increase throughout the implementation of ITIL, specifically in the later stages, which may lead to a greater strategic positioning of the IT organization.

Limitations in the study include a concentration on the United States and United Kingdom and an over-sampling of larger enterprises. As well, only the IT perception was considered. Another limitation is that empirical studies are dependent on the quality of data provided by the respondents. Also the results are based only on the perceived Business-IT alignment and on those benefits that were listed in the survey.

Since this research is targeted towards IT experts, further studies will be conducted to understand the views of the business in respect to the benefits of the ITIL implementation. A comparison of views, the IT and the business view, on these topics is relevant. Also studies will be conducted to understand how BusinessIT alignment is affected by the implementation of ITIL measuring the alignment using Luftman's SAMM.

\section{Conclusion}

Over the past years the usage of IT operational frameworks based on BPM principles such as ITIL has been on the rise. Various researchers have speculated on the possibilities of such frameworks improving process performance. Having an informed opinion on the improvements which may be provided by these frameworks is important to practitioners and researchers. In a small measure this research contributes to a better understanding of the perceived benefits provided by ITIL. 
While delivering tangible performance improvement is the goal of numerous IT managers this must not be the main objective of the IT organization. As a result, a distinction between operational effectiveness and strategy positioning must exist. As expressed earlier, both are essential but they each work in a unique form.

Both of these areas are touched by the four principal observations of this study. It shows that as the maturity of ITIL increases:

1. the perception of the level of Business-IT alignment increases

2. the number of realized benefits increases

3. the usage of metrics to measure the benefits of the implementation increases

4. the number of benefits provided by IT that are acknowledged by the business increases.

The research contributes to a better understanding of the overall benefits that can be achieved through the implementation of ITIL. It can be observed that its implementation has the potential for a strong positive effect on business performance, competitive advantage and increased profitability. Similarly, the indirect impact of the metrics and the acknowledgement of the benefits provided by IT on strategic positioning have a strong positive influence on the business.

Open Access This article is distributed under the terms of the Creative Commons Attribution Noncommercial License which permits any noncommercial use, distribution, and reproduction in any medium, provided the original author(s) and source are credited.

\section{Appendix: Survey used}

Which of the following statements best describes your IT organization?

- We have not adopted ITIL (Level 0).

- We are new to ITIL and have just started to implement processes (Level 1).

- We have a relatively low level of ITIL process maturity. Some processes are documented and these are generally understood, but errors are likely (Level 2).

- We have a medium level of ITIL process maturity. Processes are documented monitored for compliance (Level 3).

- We have a reasonably high level of ITIL process maturity. Our processes are documented, and measured according to established metrics (Level 4).

- We have a very high level of ITIL process maturity. Our processes are documented, understood, backed by metrics and continually reviewed for improvement (Level 5).

Which statement would you use to describe the relationship between IT and the business?

- Business and IT lack understanding (Level 1).

- Business and IT have a limited understanding (Level 2).

- There is a good understanding between IT and business (Level 3). 
- There is an improved and managed process of alignment (Level 4).

- There is a complete alignment with integration of strategic planning of Business and IT (Level 5).

Owing to the ITIL implementation, have you had an improvement in the following areas? (multiple answers allowed)
A. Service quality.
B. Standardized process adoption across all of IT.
C. Customer satisfaction.
D. Return on IT spending.
E. Reduction in IT downtime.
F. Benefited from best practice experience of others.
G. Financial contribution of IT to the business.
H. First-call resolution rate.
I. Improved the morale of IT staff.

(Question 4 and Question 5 are follow-up questions of Question 3. Only the factors chosen on Question 3 appear on Question 4 and Question 5).

Have the improvements in the areas been noted by the business? (multiple answers allowed)
A. Service quality.
B. Standardized process adoption across all of IT.
C. Customer satisfaction.
D. Return on IT spending.
E. Reduction in IT downtime.
F. Benefited from best practice experience of others.
G. Financial contribution of IT to the business.
H. First-call resolution rate.
I. Improved the morale of IT staff.

Have the improvements been backed by metrics? (multiple answers allowed)
A. Service quality.
B. Standardized process adoption across all of IT.
C. Customer satisfaction.
D. Return on IT spending.
E. Reduction in IT downtime.
F. Benefited from best practice experience of others.
G. Financial contribution of IT to the business.
H. First-call resolution rate.
I. Improved the morale of IT staff. 


\section{References}

Avison D, Jones J, Powell P, Wilson D (2004) Using and validating the strategic alignment model. J Strateg Inform Syst 13(3):223-246. doi:10.1016/j.jsis.2004.08.002

Banker RD, Chang H, Janakiraman SN, Konstans C (2004) A balanced scorecard analysis of performance metrics. Eur J Oper Res 154:423-436. doi:10.1016/S0377-2217(03)00179-6

Boynton A, Zmud R, Jacobs G (1994) The Influence of IT management practice on IT use in large organizations. Manage Inform Syst Q 18:14. doi:10.2307/249620

Brenner M (2006) Classifying ITIL processes. In: Proceedings of the first IEEE/IFIP international workshop on business-driven IT management (BDIM 2006)

Cater-Steel A, Toleman M, Tan WG (2006) Transforming IT service management-the ITIL impact. In: 17th Australasian conference on information systems, Adelaide, Australia

Cater-Steel A, Tan WG, Toleman M (2008) itSMF Australia 2007 conference: summary of ITSM standards and frameworks survey responses

Cervone F (2008) ITIL: a framework for managing digital library services. OCLC Syst Serv 24:87-90. doi:10.1108/10650750810875430

Conger S, Winniford MA, Erickson-Harris L (2008) Service management in operations. In: Proceedings of the fourteenth Americas conference on information systems (AMCIS), Canada

Das S, Zahra S, Warkentin M (1991) Integrating the content and process of strategic MIS planning with competitive strategy. Decis Sci 22(5):953-984

Fimbel E (2007) Alignement stratégique: synchroniser les systèmes d'information avec les trajectoires et manoeuvres des entreprises. Pearson Education France

Galup SD, Dattero R, Quan JJ, Conger S (2009) An overview of IT service management. Commun ACM 52:124-127. doi:10.1145/1506409.1506439

Hayes RH, Pisano GP (1994) Beyond world-class: the new manufacturing strategy. Harvard Bus Rev 72:77-86

Henderson JC, Venkatraman N, Oldach S (1996) Aligning business and IT strategies. Competing in the information age: strategic alignment in practice. Oxford University Press, USA, pp 21-42

Hochstein A, Tamm G, Brenner W (2005) Service-oriented IT management: benefit, cost and success factors. In: Proceedings of the thirteenth European conference on information systems, Regensburg

Hubiak WA, O’Donnell SJ (1996) Do Americans have their minds set against TQM? Nat Prod Rev 15:19-32

IT Governance Institute (2008) IT governance global status report 2008. Available at: http://www. isaca.org/[Accessed July 30, 2008]

Kaplan RS, Norton DP (1996) Using the balanced scorecard as a strategic management system. Harvard Bus Rev 74:75-87

Kashanchi R, Toland J (2006) Can ITIL contribute to IT/business alignment? An initial investigation. Wirtschaftsinformatik 48:340-348. doi:10.1007/s11576-006-0079-X

Luftman JN (2001) Assessing business-IT alignment maturity. Strateg Inform Technol 6:105-134

Luftman J (2003) Assessing business-IT alignment maturity. In: Van Grembergen W (ed) Strategies for information technology governance. IGI Global, pp 99-128

Luftman JN, Lewis PR, Oldach SH (1993) Transforming the enterprise: the alignment of business and information technology strategies. IBM Syst J 32:198-221

Luftman JN, Kempaiah R, Rigoni EH (2009) Key issues for IT executives 2008. Manage Inform Syst Q Execut 8(3):151-159

Marrone M, Kießling M, Kolbe LM (2010) Are we really innovating? An exploratory study on innovation management and service management. In: IEEE international conference on innovation and technology, Singapore

Neely A, Mills J, Platts K, Gregory M, Richards H (1994) Realizing Strategy through Measurement. Int J Oper Prod Manage 14:140. doi:10.1108/01443579410058603

Porter ME (1996) What is strategy? Harvard Bus Rev 74:61-78

Potgieter BC, Botha JH, Lew C (2005) Evidence that use of the ITIL framework is effective. In: 18th Annual conference of the national advisory committee on computing qualifications, Tauranga, NZ

Reich BH, Benbasat I (2000) Factors that influence the social dimension of alignment between business and information technology objectives. Manage Inform Syst Q 24(1):81-113. doi:10.2307/3250980

Rosenthal DR (1991) Meta-analytic procedures for social research revised. Sage Publications Inc, London 
Sabherwal R, Chan YE (2001) Alignment between business and IS strategies: a study of prospectors, analyzers, and defenders. Inform Syst Res 12:11. doi:10.1287/isre.12.1.11.9714

Spremic M, Zmirak Z, Kraljevic K (2008) IT and business process performance management: case study of ITIL implementation in finance service industry. In: 30th international conference of information technology interfaces, Croatia

Tallon PP, Kraemer KL, Gurbaxani V (2000) Executives' perceptions of the business value of information technology: a process-oriented approach. J Manage Inform Syst 16(4):145-173

van Bon J et al (2007) Foundations of IT service management based on ITIL V3: an introduction. Van Haren Publishing, Netherlands

Venkatraman N, Ramanujam V (1987) Measurement of business economic performance: an examination of method convergence. J Manage 13(1):109. doi:10.1177/014920638701300109

Winniford M, Conger S, Erickson-Harris L (2009) Confusion in the ranks: IT service management practice and terminology. Inform Syst Manage 26(2):153-163. doi:10.1080/10580530902797532

Young CM (2004) An introduction to IT service management. Gartner Res, pp 1-6

Zarnekow R, Hochstein A, Brenner W (2005) Service-orientiertes IT-management: ITIL-best-practices und Fallstudien. Springer 